\title{
Monetary Policy in the Open Economy Revisited: The Case for Exchange-Rate Flexibility Restored
}

\author{
Margarida Duarte* $\quad$ Maurice Obstfeld ${ }^{\dagger}$
}

February 2007

\begin{abstract}
This paper revisits the sticky-price pricing-to-market model of Devereux and Engel (2003), in which fixed exchange rates are optimal even in the face of country-specific nonmonetary shocks. We show that this result hinges critically on the Devereux-Engel model's prediction that international consumption levels are perfectly synchronized under flexible prices. Realistic modifications of the model that produce nonsynchronous consumption movements - such as, the presence of nontraded goods - upset the fixed exchange rate prescription even in the absence of an expenditure-switching role of exchange rate changes.
\end{abstract}

Keywords: optimal monetary policy, exchange rate variability JEL classification: F41.

*Department of Economics, University of Toronto, 150 St. George Street, Toronto, ON M5S 3G7, Canada. Tel.: +1 416978 6208. Fax: +1 416978 6713. E-mail address: margarida.duarte@utoronto.ca.

${ }^{\dagger}$ Department of Economics, University of California, Berkeley, 549 Evans Hall 3880, Berkeley, CA 94720. 


\section{Introduction}

This paper revisits the question of optimal exchange rate variability when prices cannot adjust immediately after country-specific real shocks. The traditional approach to this question dates back to Friedman (1953) and even earlier writers, who argued in favor of flexible exchange rates. In conventional open-macro models, dating back to the seminal works of Fleming and Mundell in the 1960s, imports are priced in the currency of the producer and the law of one price holds for tradable goods. The pricing assumption implies that the passthrough of an exchange rate change to import prices is complete and immediate: when a currency depreciates, for example, the prices of all imports rise immediately in proportion to the depreciation. This relative price change generates an expenditure-switching effect between home and foreign goods and lends a stabilization role to exchange rates in the face of country-specific real shocks. Empirical evidence, however, suggests that the assumptions of costless international trade and rapid, unitary pass-through are in general oversimplifications, lending further interest to the study of macromodels featuring market segmentation and pricing-to-market in international trade. ${ }^{1}$

In a pioneering paper, Devereux and Engel (2003) - DE hereafter-extend sticky-price models in the "new open economy macroeconomics" vein to incorporate price-setting in buyers' currencies by price-discriminating exporters. A key feature of the DE model is that exchange rate changes are not associated in the short run with changes in the relative import prices that confront consumers and, thus, do not generate an expenditure switching effect between local and imported goods. One might infer that in models such as DE's, featuring pricing to market and local-currency pricing, exchange rate variation cannot stabilize the economy as it does in the Mundell-Fleming model, by switching aggregate demand between home and foreign goods. And indeed, DE conclude, on the basis of a welfare analysis in their model, that fixed exchange rates are optimal even in the presence of idiosyncratic national productivity shocks. This inference would seem to overturn the conventional wisdom that country-specific real shocks make exchange-rate flexibility desirable. See Engel (2002) for an elaboration of this theme.

In this paper, we demonstrate that flexible exchange rates are optimal in realistic variants

\footnotetext{
${ }^{1}$ See Goldberg and Knetter (1997) for a survey of international pricing. On trade costs in general, see Anderson and van Wincoop (2004).
} 
of the DE model which still feature a complete absence of expenditure-switching effects of exchange rate changes. In our model, it is optimal for monetary authorities to affect domestic aggregate demand differently in response to country-specific real shocks, implying a flexible exchange rate under optimal policies. In DE's model, the optimality of fixed exchange rates is primarily due to a knife-edge and unrealistic symmetry restriction embedded in their model that eliminates the need for distinct effects of monetary policy on aggregate demand across countries. We emphasize that DE's result is not due to the absence of expenditure-switching effects of exchange rate changes. It is important to stress that we are not simply making the point that an absence of expenditure-switching exchange rate effects on consumer spending leaves room for exchange-rate flexibility. ${ }^{2}$ Instead, we show that even a complete absence of expenditure-switching effects need not nullify the case for flexible exchange rates in more realistic variants of the DE model. The specific modification we make to the DE model is to add nontradable goods, although our analysis suggests that a number of alternative plausible modifications would have a similar effect on the model's predictions about optimal monetary policy. ${ }^{3}$ Our conclusion is that while more detailed theorizing about open-economy price rigidities is extremely valuable, the channels of monetary policy transmission can be subtle and researchers should accordingly be cautious in leaping to radical policy conclusions.

\section{Intuition for the Basic Result}

A central building block of DE's model is an assumption of complete international asset markets. With segmentation across national goods markets, but free trade in international asset markets, prices of state-contingent claims to future money payments are equalized internationally. That equality leads to the condition for international risk sharing tested by Backus and Smith (1993). Let $C$ denote a consumption index, $P$ the overall money price level, $S$ the exchange rate (domestic price of foreign currency), and let asterisks denote the corresponding foreign variables. Furthermore, for simplicity assume a constant coefficient of

\footnotetext{
${ }^{2}$ Thus, Obstfeld and Rogoff (2000) argue that the pass-through of exchange rates to producer prices is relevant. Following up on this point, Obstfeld (2001) presents a formal analysis in which producers respond to the implied relative-price changes, even though relative consumer prices are all predetermined.

${ }^{3}$ Duarte (2004) and Obstfeld (2004) demonstrate the case for flexible exchange rates in models with pricing-to-market in local currency and nontraded goods. Duarte works with a variant of the model of Corsetti and Pesenti (2001). Obstfeld uses a variant of the DE model in which the nominal interest rate is the monetary policy instrument and shocks can be temporary.
} 
relative risk aversion, $\rho$. Then the Backus-Smith risk-sharing condition takes the form:

$$
\frac{C_{t+1}^{-\rho} / P_{t+1}}{C_{t}^{-\rho} / P_{t}}=\frac{\left(C_{t+1}^{*}\right)^{-\rho} / S_{t+1} P_{t+1}^{*}}{\left(C_{t}^{*}\right)^{-\rho} / S_{t} P_{t}^{*}}
$$

That is, the growth rate of the marginal consumption value of a currency unit is equal across countries in all states of nature.

In the DE model, $C$ and $C^{*}$ always move together under flexible prices. More importantly, because of risk sharing, $C$ and $C^{*}$ move together even when one country alone experiences a change in its technological productivity. In a number of models with sticky prices, for instance, Obstfeld and Rogoff (2000), optimal monetary policy simply replicates the flexibleprice equilibrium. In general that is impossible with local-currency pricing, because monetary policy lacks any capacity to alter the relative prices that consumers face, notwithstanding technological or other shocks that might render those prices obsolete. As DE prove, however, the responses of consumptions to real shocks are the same under optimal monetary policies as under flexible prices. That is, in response to country-specific real shocks, both countries experience proportionally equal changes in consumption.

That finding immediately leads to the prescription that exchange rates should remain fixed in the face of idiosyncratic real shocks. Consider the preceding risk sharing condition. Suppose that an unexpected increase in home productivity occurs, that the exchange rate is fixed, and that price levels do not respond to this shock in the short run. Under optimal monetary policies, $C$ and $C^{*}$ rise in proportion. Since price levels cannot move, the risk sharing condition, continues to hold without an exchange rate change.

Conversely, however, suppose that, home and foreign consumptions do not move in proportion under flexible prices. This is the case with nontraded goods, which cause the overall consumption indexes $C$ and $C^{*}$ to respond disproportionately strongly to domestic productivity shocks. ${ }^{4}$ As we show below, even with nontradables, it is still feasible and optimal for monetary policies to mimic the flexible-price responses of consumption to real shocks. In that case, however, the rigidity of price levels implies that the exchange rate must move under optimal policies. The risk-sharing condition shows why: if consumptions move asymmetrically, only an exchange rate change can preserve the marginal equality above. In general,

\footnotetext{
${ }^{4}$ Other preference assumptions — such as domestic preference for domestic tradable goods — would produce the same effect.
} 
countries that experience idiosyncratic productivity increases will also experience currency depreciation under optimal monetary policies.

\section{The Model}

We extend the model specification proposed by DE to include nontradable consumption goods. Considering nontradable goods in open-economy macro models is relevant for at least two reasons. First, nontradable goods form a substantial portion of aggregate consumption baskets. ${ }^{5}$ Second, the presence of nontradable goods generates asymmetries across countries that are relevant for the study of optimal monetary responses to country-specific non-monetary shocks.

There are two countries, denoted home and foreign, and each country is inhabited by a unit mass of identical consumers. A country's firms produce a continuum of tradable goods and a continuum of nontradable goods, with each producer being a monopolistic supplier of a variety. Varieties of goods (tradable and nontradable) are indexed by $i \in[0,1]$ in the home country and by $i^{*} \in[0,1]$ in the foreign country. ${ }^{6}$

Markets for tradable goods are internationally segmented, such that consumers face infinite costs in purchasing tradables abroad. A producer of tradable goods may, however, sell domestically or abroad, and the assumed market segmentation allows the producer to price-discriminate on the basis of consumer nationality. We assume that producers set prices in the customers' currency a period in advance of sales, delivering all the supply demanded at that preset local-currency price. Therefore, there are no expenditure-switching effects between local and imported goods associated with exchange rate changes.

The two countries are (ex-ante) symmetric and we will only describe the home economy. Foreign variables are denoted with an asterisk.

\footnotetext{
${ }^{5}$ See, for example, Stockman and Tesar (1995) who argue that the share of nontradable goods in private final consumption in OECD countries ranges from 30 to 50 percent. Indeed, when one recognizes that the retail prices of supposedly "tradable" consumer goods incorporate important nontradable components such as advertising and domestic shipping, the share of nontradables in GDP is more likely to be closer to 75 percent.

${ }^{6}$ To make our points most simply, we assume equally-sized countries.
} 
A representative consumer maximizes

$$
U_{0}=\mathrm{E}_{0}\left\{\sum_{t=0}^{\infty} \beta^{t}\left[\frac{C_{t}^{1-\rho}}{1-\rho}+\frac{\chi}{1-\varepsilon}\left(\frac{M_{t}}{P_{t}}\right)^{1-\varepsilon} V_{t}-\eta L_{t}\right]\right\},
$$

where $M$ stands for domestic money holdings, $V$ is a shock to money demand, $L$ is labor supply, $\eta, \rho>0$, and $\beta \in(0,1)$. Consumers have access to complete markets for statecontingent money payoffs; they receive labor income $W L$ from firms, dividends $\Pi$ from domestic firms, and transfers $T$ from the government; consumption expenditures are $P C$.

The overall consumption index $C$ depends on consumption of nontradables (subscript $N$ ) as well as tradables (subscript $T$ ),

$$
C=\frac{C_{T}^{\gamma} C_{N}^{1-\gamma}}{\gamma^{\gamma}(1-\gamma)^{1-\gamma}}
$$

with the special case $\gamma=1$ delivering the DE model. The tradables subindex, $C_{T}$, depends on consumption levels for tradables originating in the home and foreign countries,

$$
C_{T}=\frac{C_{H}^{\varphi} C_{F}^{1-\varphi}}{\varphi^{\varphi}(1-\varphi)^{1-\varphi}}
$$

The corresponding tradables subindex for the representative foreign agent is

$$
C_{T}^{*}=\frac{\left(C_{H}^{*}\right)^{\varphi^{*}}\left(C_{F}^{*}\right)^{1-\varphi^{*}}}{\varphi^{* \varphi^{*}}\left(1-\varphi^{*}\right)^{1-\varphi^{*}}}
$$

When $\varphi=\varphi^{*}$, as assumed by DE, preferences for tradable goods are identical across countries. The parameter restriction $\varphi=\varphi^{*}$ does not allow for the empirical consumption bias toward tradable goods produced locally (which would be consistent with the alternative parameter restrictions $\varphi>0.5$ and $\left.1-\varphi^{*}>0.5\right)$. Hereafter, however, we follow DE in assuming that $\varphi=\varphi^{*}$, and we specialize further to the case in which $\varphi=\varphi^{*}=1 / 2$. This choice does not reduce in any essential way the generality of our results. ${ }^{7}$

The home and foreign tradables sub-indices $C_{H}$ and $C_{F}$ are constant-elasticity-of-substitution aggregates of the quantity consumed of all varieties of the good, $C_{H}(i)$ and $C_{F}\left(i^{*}\right)$, respectively. The elasticity of substitution between differentiated varieties is $\lambda$, with $\lambda>1$.

\footnotetext{
${ }^{7}$ Generalizing the DE setup by allowing $\varphi \neq \varphi^{*}$, instead of considering nontradable goods, would likewise generate a stabilization role for exchange rate changes.
} 
The aggregate price index and the price index for tradable goods are given by

$$
P=P_{T}^{\gamma} P_{N}^{1-\gamma}
$$

and

$$
P_{T}=P_{H}^{\frac{1}{2}} P_{F}^{\frac{1}{2}}
$$

where the price indices for home and foreign tradable goods and nontradable goods are

$$
P_{j}=\left\{\begin{array}{l}
{\left[\int_{0}^{1} P_{j}(i)^{1-\lambda} d i\right]^{\frac{1}{1-\lambda}}, \quad j=H, N,} \\
{\left[\int_{0}^{1} P_{j}\left(i^{*}\right)^{1-\lambda} d i^{*}\right]^{\frac{1}{1-\lambda}}, \quad j=F .}
\end{array}\right.
$$

There are two sectors of production in each country. As we have noted, firms in each sector are monopolistic competitors. The production function for firms in the home country is given by

$$
Y_{j}(i)=\theta L_{j}(i), \quad j=H, N
$$

The random variable $\theta$ represents the economy-wide country-specific productivity level of the home country. ${ }^{8}$

The government prints the local currency and distributes it to consumers. The gross growth rate of the $\log$ of the money supply is denoted by $\mu_{t}$. Monetary policy will be described by a rule for $\mu$.

The model is driven by shocks to money demand (velocity) and productivity in each country. We assume that the log technology and velocity shocks follow random walks, with $u_{t}$ and $u_{t}^{*}$ denoting the innovations in log technology and $v_{t}$ and $v_{t}^{*}$ those in log velocity. The innovations $u_{t}, u_{t}^{*}, v_{t}$, and $v_{t}^{*}$ are mean-zero i.i.d. normally distributed random variables. In addition, innovations are independent across countries.

\footnotetext{
${ }^{8}$ For simplicity, we abstract from sector-specific productivity shocks. Although sector-specific shocks would complicate the model's implied optimal monetary rules, welfare-maximizing monetary policies would still respond to the economy-wide average of sector-specific shocks as we describe below.
} 


\section{The Flexible-Price Consumption Equilibrium}

When prices are flexible, all firms set prices as a constant markup, $\lambda /(1-\lambda)$, over nominal marginal cost $\left(W / \theta\right.$ for firms located in the home country and $W^{*} / \theta^{*}$ for firms located in the foreign country). Using the first-order optimality conditions for individual consumption, one can show that aggregate consumption levels are given by

$$
C_{t}=\left[\left(\frac{\lambda-1}{\lambda \eta}\right)\left(\theta_{t} \theta_{t}^{*}\right)^{\frac{\gamma}{2}} \theta_{t}^{1-\gamma}\right]^{\frac{1}{\rho}}
$$

in the home country and

$$
C_{t}^{*}=\left[\left(\frac{\lambda-1}{\lambda \eta}\right)\left(\theta_{t} \theta_{t}^{*}\right)^{\frac{\gamma}{2}}\left(\theta_{t}^{*}\right)^{1-\gamma}\right]^{\frac{1}{\rho}}
$$

in the foreign country. ${ }^{9}$

When all goods are tradable $(\gamma=1)$, consumption is equalized across countries, as it depends on the same combination of home and foreign productivity levels. In contrast, when some goods are nontradable (i.e., $\gamma<1$ ), a country's consumption level depends disproportionately on its own aggregate productivity level — domestic nontraded goods, by definition, cannot be shipped abroad to augment foreigners' consumption. Therefore, consumption levels need not be equalized across countries, or move in a synchronized fashion, with flexible prices.

The possibility of an asymmetric equilibrium consumption response under flexible prices suggests that, under sticky prices, the optimal responses of monetary policies to countryspecific shocks may differ across countries. If so, the nominal exchange rate would have to vary under optimal monetary policies. We will now see that this intuition is correct. Optimal monetary policy, while not able to replicate flexible-price levels of consumption, does replicate flexible-price consumption responses to shocks. Because these responses may differ internationally when $\gamma<1$, countries' best monetary policy rules must allow exchange rates to move. ${ }^{10}$

\footnotetext{
${ }^{9}$ Derivations of all expressions below can be found in an appendix available from the authors upon request.

${ }^{10} \mathrm{With}$ transitory rather than permanent productivity shocks, asymmetric consumption responses would lead to international real and nominal interest differentials; see Obstfeld (2004).
} 


\section{The Equilibrium with Preset Nominal Prices}

In the sticky-price version of the model, firms choose the nominal prices for their goods one period in advance so as to maximize expected profits. Firms choose a home-currency price for domestic sales and a foreign-currency price for exports: This is the assumption of pricingto-market in local rather than producer currency. The local-currency pricing specification is broadly consistent with empirical evidence documenting a small short-run response of consumer prices, even for imported goods, to changes in the nominal exchange rate. The optimal prices for the home producer $i$ of tradable and nontradable goods sold in the home market are

$$
P_{j, t}(i)=\frac{\lambda}{\lambda-1} \frac{\mathrm{E}_{t-1}\left[C_{t}^{1-\rho} \frac{W_{t}}{\theta_{t}}\right]}{\mathrm{E}_{t-1}\left[C_{t}^{1-\rho}\right]}, \quad j=h, N,
$$

while the foreign-currency price used for export sales of the home good is

$$
P_{H, t}^{*}(i)=\frac{\lambda}{\lambda-1} \frac{\mathrm{E}_{t-1}\left[C_{t}^{* 1-\rho} \frac{W_{t}}{S_{t} \theta_{t}}\right]}{\mathrm{E}_{t-1}\left[C_{t}^{* 1-\rho}\right]} .
$$

The nominal exchange rate, $S_{t}$, is the home-currency price of foreign currency. There are corresponding formulas for foreign-based producers, dependent on foreign nominal marginal cost, $W_{t}^{*} / \theta_{t}^{*}$.

Let lower-case letters denote the logs of variables denoted by upper-case letters. It can be shown that in our model, (log) consumption innovations are given by

$$
c_{t}-\mathrm{E}_{t-1} c_{t}=\phi\left(\mu_{t}-\frac{\nu_{t}}{\varepsilon}\right)+\psi\left[\frac{\gamma}{2}\left(u_{t}+u_{t}^{*}\right)+(1-\gamma) u_{t}\right]
$$

and

$$
c_{t}^{*}-\mathrm{E}_{t-1} c_{t}^{*}=\phi\left(\mu_{t}^{*}-\frac{\nu_{t}^{*}}{\varepsilon}\right)+\psi\left[\frac{\gamma}{2}\left(u_{t}+u_{t}^{*}\right)+(1-\gamma) u_{t}^{*}\right],
$$

where $\phi=(1+i \varepsilon) /(\rho(1+i))$ and $\psi=(\varepsilon-1) /(\rho \varepsilon(1+i))$, and $i$ denotes the (level of the) steady-state nominal interest rate.

Because there are nontradable goods, consumption innovations depend on numerically different combinations of home and foreign productivity shocks. As one would expect, innovations to consumption depend disproportionately on the local productivity shock. In contrast, when all goods are tradable (so that $\gamma=1$ ), innovations to consumption in each 
country depend on the same combination of productivity shocks, $\left(u_{t}+u_{t}^{*}\right) / 2$. This feature of the model follows from the extreme symmetry of the model when $\gamma=1$, including the assumption of complete markets. In the absence of nontradables, preferences are identical across countries and are defined over the same basket of goods.

Since the presence of nontradable goods implies that productivity shocks have distinct effects on consumption across countries, it follows that, in equilibrium, the nominal exchange rate can also depend on productivity shocks. In our model, changes in the exchange rate are given by

$$
s_{t}-s_{t-1}=\rho \psi(1-\gamma)\left(u_{t}-u_{t}^{*}\right)+\rho \phi\left[\mu_{t}-\mu_{t}^{*}-\frac{1}{\varepsilon}\left(\nu_{t}-\nu_{t}^{*}\right)\right]-\frac{i(\varepsilon-1)}{1+i}\left[p_{t}-p_{t-1}-\left(p_{t}^{*}-p_{t-1}^{*}\right)\right] .
$$

When all goods are tradable, changes in the nominal exchange rate do not depend on countryspecific real shocks (in the absence of monetary rules that target these shocks). With nontradables, the exchange rate does respond to country-specific real shocks if $\psi \neq 0$ (which is true if and only if $\varepsilon \neq 1$ ).

\section{Optimal Monetary Policies}

We now turn to the implications of nontradable goods for optimal monetary policies. We assume that the monetary authority in each country commits to preannounced state-contingent monetary policy feedback rules. These are chosen to maximize the (nonmonetary) expected utility of the country's representative consumer, taking the other country's monetary rule as given. ${ }^{11}$ We consider monetary rules that are log-linear functions of innovations to productivity levels and velocity: $\mu_{t}=a_{1} u_{t}+a_{2} u_{t}^{*}+a_{3} \nu_{t}+a_{4} \nu_{t}^{*}$ in the home country and $\mu_{t}^{*}=b_{1} u_{t}^{*}+b_{2} u_{t}+b_{3} \nu_{t}^{*}+b_{4} \nu_{t}$ in the foreign country.

The Nash equilibrium in monetary policies is defined as the set $\left\{a^{N}, b^{N}\right\}$, where $a=$ $\left\{a_{1}, a_{2}, a_{3}, a_{4}\right\}$ and $b=\left\{b_{1}, b_{2}, b_{3}, b_{4}\right\}$, which solve

$$
\max _{a} \mathrm{E}_{0} U\left(a, b^{N}\right)
$$

\footnotetext{
${ }^{11}$ Formally, we look at policies optimal as $\chi \rightarrow 0$ in the utility function $U_{0}$ described above.
} 
and

$$
\max _{b} \mathrm{E}_{0} U^{*}\left(a^{N}, b\right)
$$

subject to the model's structural equations for consumption and labor effort in the two countries.

The solution to problems (6) and (7) is given by

$$
a_{1}^{N}=\frac{\gamma}{2 \varepsilon}+\frac{1-\gamma}{\varepsilon}, a_{2}^{N}=\frac{\gamma}{2 \varepsilon}, a_{3}^{N}=\frac{1}{\varepsilon}, a_{4}^{N}=0
$$

and

$$
b_{1}^{N}=\frac{\gamma}{2 \varepsilon}+\frac{1-\gamma}{\varepsilon}, b_{2}^{N}=\frac{\gamma}{2 \varepsilon}, b_{3}^{N}=\frac{1}{\varepsilon}, b_{4}^{N}=0 .
$$

In the absence of nontradable goods, optimal monetary policy rules place the same weight on local and foreign productivity shocks. It follows from equation (5) that the nominal exchange rate remains constant following country-specific real shocks. This result replicates Proposition 2 of DE (p. 778). In contrast, when some goods are nontradable monetary authorities place a bigger weight on the local productivity shock than on the productivity shock originating abroad. It follows that the nominal exchange rate is not constant in general. That is, optimal monetary policies need not support a fixed exchange rate regime when some goods are nontradable. ${ }^{12}$ In fact, it can be seen that the conditional variance of the exchange rate under optimal policies is proportional to the fraction of nontradable goods, $(1-\gamma)$, and is given by

$$
\operatorname{var}_{t-1}\left(s_{t}\right)=(1-\gamma)^{2}\left[\operatorname{var}\left(u_{t}\right)+\operatorname{var}\left(u_{t}^{*}\right)\right]
$$

The reader can now verify that, as claimed earlier, the responses of total consumption levels to technology shocks under optimal monetary policies are the same as in the flexibleprice equilibrium. For example, equation (1) implies that under the flexible-price allocation,

$$
\frac{\mathrm{d} c}{\mathrm{~d} u}=\frac{1}{\rho}\left(1-\frac{\gamma}{2}\right)
$$

Under optimal monetary policy, however, we have the same result, for equation (3) implies

\footnotetext{
${ }^{12}$ It turns out that the Nash equilibrium actually is efficient - each country's equilibrium rule is a dominant strategy. This is also true in DE, but it is perhaps more surprising that the same result emerges when exchange rates vary.
} 
that

$$
\begin{aligned}
\frac{\mathrm{d} c}{\mathrm{~d} u} & =\phi \underbrace{\left(\frac{\mathrm{d} \mu}{\mathrm{d} u}\right)}_{a_{1}^{N}}+\psi\left(1-\frac{\gamma}{2}\right), \\
& =\frac{1}{\rho}\left(1-\frac{\gamma}{2}\right) .
\end{aligned}
$$

Thus, as we argued earlier, asynchronous international consumption movements under flexible prices underlie the case for exchange-rate flexibility in this model. The nature of international consumption movements under flexible prices is determined in a simple way in this model by the specification of preferences. When preferences are identical across countries the DE result that fixed exchange rates are optimal follows. However, under more empirically plausible specifications where agents in different countries may have different preferences (by assuming that home and foreign agents value different baskets of goods nontraded goods - or that they value differently the same basket of goods - bias) it follows that exchange rates are flexible under optimal monetary policies.

In our model, the absence of expenditure-switching effects of exchange rate changes does not eliminate the optimality of exchange rate fluctuations in response to country-specific real shocks: With nontradable goods, it is optimal for the exchange rate to fluctuate in order to accommodate the efficient response of aggregate consumption. It should be noted, however, that the absence of expenditure-switching effects of exchange rate changes affects the magnitude of optimal exchange rate fluctuations in our model. In the conventional case in which firms set prices in the currency of the producer and exchange rate changes generate expenditure-switching effects, optimal monetary polices in our model replicate the flexible price equilibrium, even in the presence of nontradable goods. ${ }^{13}$ In this case, the optimal exchange rate response to country-specific real shocks always replicates all relative prices that consumers face under the flexible-price equilibrium and the conditional variance of the

\footnotetext{
${ }^{13} \mathrm{DE}$ show that optimal monetary policies replicate that flexible price equilibrium when firms set prices in the currency of the producer and asset markets are complete. Note that in our model with nontradable goods technology shocks are not sector specific. Therefore, the relative price of nontradable to tradable goods is one, both in the equilibrium with flexible prices and sticky prices, and optimal monetary policies are not affected by the presence of nontradable goods.
} 
exchange rate under optimal monetary policies is

$$
\operatorname{var}_{t-1}\left(s_{t}\right)=\operatorname{var}\left(u_{t}\right)+\operatorname{var}\left(u_{t}^{*}\right) .
$$

That is, in this case, the optimal degree of exchange rate volatility is not affected by the presence of nontraded goods, in contrast to the case of local-currency pricing described in equation (10). Moreover, for a given weight of nontradable consumption, the optimal degree of exchange rate volatility is higher when firms set prices in the currency of the producer than in the absence of expenditure-switching effects.

\section{Conclusion}

Taken together, DE and this paper suggest caution in analyzing the transmission mechanisms for monetary policy in open economies with complex price rigidities. The DE paper makes an important advance in demonstrating how alternative price-setting arrangements in open economies can alter the transmission mechanism. A distinct advantage of the new open economy macroeconomics approach is its accommodation of the detailed modelling of price-setting regimes, coupled with an exact analysis of the general-equilibrium welfare implications. In reality, national consumption movements are asymmetrical and international asset markets are incomplete. We therefore think it unlikely that optimal monetary responses to country-specific real shocks would ever imply rigid exchange rates in practice. Both DE and this paper, moreover, suggest that the sources of low exchange rate pass-through to consumer prices affect the optimal degree of exchange rate volatility. Like DE, we have limited our analysis to the qualitative dimensions of monetary policy, leaving for the future a close quantitative study of how alternative pricing arrangements and economic structures affect the optimal amount of exchange-rate volatility. 


\section{References}

[1] Anderson, J.E., van Wincoop, E., 2004. Trade Costs. Journal of Economic Literature $42(3), 691-751$.

[2] Backus, D., Smith, G.W., 1993. Consumption and Real Exchange Rates in Dynamic Economies with Non-Traded Goods. Journal of International Economics 35 (November), 297-316.

[3] Corsetti, G., Pesenti, P., 2001. International Dimensions of Optimal Monetary Policy. National Bureau of Economic Research Working paper No. 8230.

[4] Devereux, M.B., Engel, C., 2003. Monetary Policy in the Open Economy Revisited: Price Setting and Exchange-Rate Flexibility. Review of Economic Studies 70 (October), 765-783.

[5] Duarte, M., 2004. Monetary Policy and the Adjustment to Country-Specific Shocks. Federal Reserve Bank of Richmond Economic Quarterly 90 (2), 21-40.

[6] Engel, C., 2002. Expenditure Switching and Exchange-Rate Policy. NBER Macroeconomics Annual 2002 17, 231-272.

[7] Friedman, M., 1953. The Case for Flexible Exchange Rates. In: Essays in Positive Economics. The University of Chicago Press, Chicago, 157-203.

[8] Goldberg, P.K., Knetter, M.M., 1997. Goods Prices and Exchange Rates: What Have we Learned?. Journal of Economic Literature 35 (September), 1243-1272.

[9] Obstfeld, M., 2001. International Macroeconomics: Beyond the Mundell-Fleming Model. International Monetary Fund Staff Papers 47, 1-39.

[10] Obstfeld, M., 2004. Pricing-to-Market, the Interest-Rate Rule, and the Exchange Rate. Manuscript, University of California, Berkeley.

[11] Obstfeld, M., Rogoff, K., 2000. New Directions for Stochastic Open Economy Models. Journal of International Economics 50 (1), 117-153. 
[12] Stockman, A.C., Tesar, L., 1995. Tastes and Technology in a Two-Country Model of the Business Cycle: Explaining International Comovements. American Economic Review 85 (1), 168-185. 